\title{
The Epidemiology of Diabetes in Korea
}

\author{
Dae Jung Kim \\ Department of Endocrinology and Metabolism, Ajou University School of Medicine, Suwon, Korea
}

Diabetes is an increasing global health problem worldwide. Diabetes and its complications have become a major cause of morbidity and mortality in Korea. The prevalence of diabetes in Korea has increased six- to seven-fold from 1.5\% to $9.9 \%$ in the past 40 years. The prevalence of impaired fasting glucose also increased to about $20 \%$ in 2009. The International Diabetes Federation has estimated that the prevalence of diabetes will rise to $11.4 \%$ in 2030. Possible risk factors for diabetes in Korea are age, male gender, obesity, prediabetes, gestational diabetes, smoking, decreased physical activity, and short sleep duration. With increasing obesity, especially in childhood, and improved longevity, the prevalence of diabetes is expected to dramatically increase more than previously estimated. Therefore, public efforts to introduce healthy lifestyle changes and diabetic prevention programs are necessary to reduce the global epidemic of diabetes.

Keywords: Diabetes mellitus; Epidemiology; Incidence; Prediabetic state; Prevalence

\section{INTRODUCTION}

Diabetes is an increasing global health problem [1]. The increased prevalence is likely attributable to rapid economic development, improved living standards, an aging population, and a Westernized lifestyle. Diabetes and its complications have become a major cause of morbidity and mortality in Korea [2]. Although diabetes-related mortality has recently decreased from 25.1 per 100,000 persons in 2002 to 19.6 per 100,000 persons in 2009, diabetes is still the fifth-leading cause of death in Korea [2]. Diabetic complications such as renal failure, neuropathy, retinopathy, coronary and cerebral artery diseases, and amputations are associated with increased medical costs and reduced life expectancy [3].

\section{PREVALENCE OF DIABETES AND PREDIABETES: A COHORT STUDY}

The first epidemiologic study on diabetes was conducted in the rural area of Okku-gun, Chollabuk-do, in 1971 [4]. With the criteria of $\geq 160 \mathrm{mg} / \mathrm{dL}$ for 1-hour glucose and $\geq 110 \mathrm{mg} /$ $\mathrm{dL}$ for 2-hour glucose after a $50 \mathrm{~g}$ oral glucose tolerance test (OGTT), the prevalence of diabetes was $0.91 \%$ ( $1.41 \%$ of males, $0.42 \%$ of females) among the total subjects aged $\geq 10$ years, and $1.5 \%$ ( $2.5 \%$ of males, $0.7 \%$ of females) among adults aged $\geq 30$ years (Table 1 ).

In the 1980s, there was a large, healthcare center-based survey on the prevalence of diabetes [5]. After the $50 \mathrm{~g}$ OGTT, diabetes was diagnosed with criteria of fasting glucose $\geq 140$ $\mathrm{mg} / \mathrm{dL}$ and 1-hour glucose $\geq 200 \mathrm{mg} / \mathrm{dL}$. The prevalence of diabetes among subjects aged $\geq 10$ years was $3.5 \%$ ( $4.2 \%$ of males, $2.4 \%$ of females). The prevalence of diabetes increased according to age: $2.2 \%, 0.5 \%, 0.9 \%, 3.4 \%, 7.1 \%, 10.4 \%$, and $10.7 \%$ in the second to eighth decades, respectively. The prevalence of impaired glucose tolerance (IGT) was 8.0\%.

In the 1990s, there were many epidemiologic studies on diabetes prevalence. According to the data from the Korea Medical Insurance Corporation (KMIC), which provides insurance
Corresponding author: Dae Jung Kim

Department of Endocrinology and Metabolism, Ajou University School of

Medicine, San 5 Woncheon-dong, Yeongtong-gu, Suwon 443-721, Korea

E-mail: djkim@ajou.ac.kr
This is an Open Access article distributed under the terms of the Creative Commons Attribution Non-Commercial License (http://creativecommons.org/licenses/by-nc/3.0/) which permits unrestricted non-commercial use, distribution, and reproduction in any medium, provided the original work is properly cited. 
Table 1. Prevalence of diabetes and prediabetes among Koreans: the cohort data

\begin{tabular}{|c|c|c|c|c|c|}
\hline Reference & $\begin{array}{l}\text { Year of study; } \\
\text { Data source }\end{array}$ & $\begin{array}{l}\text { Test method and } \\
\text { criteria }\end{array}$ & Sample size & Age, yr & Prevalence (\%) \\
\hline$[4]$ & 1971; Rural & $50 \mathrm{~g}$ OGTT & 15,853 & $\geq 10$ & $\begin{array}{l}\text { DM: } 0.91 \%(M, 1.41 \% ; F, 0.42)(\geq 10 y r) \\
1.5 \%(M, 2.5 \% ; F, 0.7 \%)(\geq 30 y r)\end{array}$ \\
\hline [5] & $\begin{array}{l}\text { 1980-1983; } \\
\text { Health care center }\end{array}$ & $\begin{array}{l}50 \mathrm{~g} \text { OGTT } \\
\text { NDDG }\end{array}$ & 18,201 & $\geq 10$ & $\begin{array}{l}\text { DM: } 3.5 \%(M, 4.2 \% ; F, 2.4 \%) \\
\text { IGT: } 8.0 \%\end{array}$ \\
\hline$[6]$ & 1990-1992; KMIC & $\mathrm{FPG} \geq 126 \mathrm{mg} / \mathrm{dL}$ & $\begin{array}{l}\mathrm{M}, 115,200 \\
\mathrm{~F}, 67,861\end{array}$ & $35-59$ & DM: M, 4.7\%; F, 1.3\% \\
\hline [7] & 1993; Rural & $\begin{array}{l}75 \text { g OGTT } \\
\text { WHO }\end{array}$ & 2,520 & $30-64$ & $\begin{array}{l}\text { DM: } 7.2 \% \\
\text { IGT: } 8.9 \%\end{array}$ \\
\hline$[8]$ & 1997; Rural & $\begin{array}{l}75 \mathrm{~g} O G T \mathrm{~T} \\
\text { WHO/ADA }\end{array}$ & 1,108 & $\geq 40$ & $\begin{array}{l}\text { DM: } 7.1 \%(\mathrm{WHO}), 8.5 \%(\mathrm{ADA}) \\
\text { IGT: } 8.5 \%(\mathrm{WHO}), 11.1 \%(\mathrm{IGT} / \mathrm{IFG}, \mathrm{ADA})\end{array}$ \\
\hline [9] & 1998; Urban & $\begin{array}{l}75 \text { g OGTT } \\
\text { WHO }\end{array}$ & 774 & $\geq 30$ & $\begin{array}{l}\text { DM: } 8.5 \%(M, 13.6 \% ; F, 5.8 \%) \\
\text { IGT: } 7.8 \%(M, 8.3 \% ; F, 7.6 \%)\end{array}$ \\
\hline$[10]$ & $\begin{array}{l}\text { 2001-2002; } \\
\text { Rural, urban }\end{array}$ & $\begin{array}{l}75 \text { g OGTT } \\
\text { ADA }\end{array}$ & 10,038 & $40-69$ & $\begin{array}{l}\text { DM: } 12.6 \% \text { (known DM 6.0\%, } \\
\text { newly diagnosed DM 6.6\%) }\end{array}$ \\
\hline
\end{tabular}

OGTT, oral glucose tolerance test; DM, diabetes mellitus; NDDG, National Diabetes Data Group; IGT, impaired glucose tolerance; KMIC, Korea Medical Insurance Corporation; FPG, fasting plasma glucose; WHO, World Health Organization; ADA, American Diabetes Association; IFG, impaired fasting glucose.

to civil servants and private school workers aged 35 to 59, the prevalence of diabetes was defined as a mean fasting blood glucose of $\geq 126 \mathrm{mg} / \mathrm{dL}$ in 1990 to 1992 was $4.7 \%$ in men and $1.3 \%$ in women [6]. The prevalence of diabetes in the KMIC cohort may be underestimated because OGTTs were not performed and KMIC workers tend to be healthier than the general population.

A well-designed population-based cohort study was first conducted in Yonchon County in 1993 [7]. A total of 2,520 participants underwent a standard $75 \mathrm{~g}$ OGTT. The prevalence of diabetes was $7.2 \%$, substantially higher than that in the previous study, and the prevalence of IGT was $8.9 \%$.

Another population-based study was performed in Jungup District in 1997 [8]. Among 1,108 subjects who completed the $75 \mathrm{~g}$ OGTT, the prevalence of diabetes and IGT as defined by the World Health Organization (WHO) criteria were $7.1 \%$ and $8.5 \%$, respectively, after correction for Segi's standard world population. When the 1997 American Diabetes Association (ADA) criteria were employed, the prevalence of diabetes and IGT increased to $8.5 \%$ and $11.1 \%$, respectively.

An epidemiologic study of diabetes in Korean urban communities was performed in Mokdong, Seoul, in 1998 [9]. There was an $8.5 \%$ prevalence of diabetes and $7.8 \%$ prevalence of impaired glucose regulation (IGR), including IGT and impaired fasting glucose (IFG). The age-adjusted prevalence of diabetes and IGR was $8.4 \%$ and $7.1 \%$, respectively. Interesting- ly, the prevalence of diabetes in the urban area was slightly higher than that in the rural area.

The Korea Center for Disease Control designed a prospective, large-scale, community-based cohort study [10,11]. In a baseline study in 2001 to 2002, the prevalence of diabetes was $12.6 \%$, including 6.0\% known diabetes and 6.6\% newly diagnosed diabetes. Accordingly, there was a rapid and dramatic increase in diabetes in Korea.

\section{PREVALENCE OF DIABETES AND PREDIABETES: A NATIONAL SURVEY}

With increased attention to social welfare in Korea, the Ministry of Health and Welfare conducted a series of Korea National Health and Nutrition Examination Surveys (KNHANES) to examine the general health and nutrition status of Koreans [12].

The prevalence of diabetes among adults aged $\geq 30$ years in $1998,2001,2005$, and 2007-2009 was $11.1 \%, 8.9 \%, 9.1 \%$, and $9.9 \%$, respectively. The proportion of known cases of diabetes drastically increased from $23.2 \%$ in 1998 to $41.2 \%$ in 2001 , $68.0 \%$ in 2005 and $72.3 \%$ in $2007-2009$. The prevalence of IFG also increased from $17.4 \%$ in 2005 to $20.4 \%$ in $2007-2009$ (Table 2).

Diabetes and IFG increased dramatically with age in 20072009 (Table 3, Fig. 1). Among patients 60 years of age or older, the prevalence of diabetes was estimated to be about $20 \%$, and 
Table 2. Prevalence of diabetes and IFG among Korean adults: the KNHANES study

\begin{tabular}{|c|c|c|c|c|c|c|}
\hline Reference & $\begin{array}{l}\text { Year of study; } \\
\text { Data source }\end{array}$ & Test method and criteria & $\begin{array}{l}\text { Sample } \\
\text { size }\end{array}$ & Age, yr & $\begin{array}{c}\text { Prevalence of diabetes and } \\
\text { IFG }(\%)\end{array}$ & $\begin{array}{c}\text { Proportion of } \\
\text { known diabetes, } \%\end{array}$ \\
\hline [12] & 1998; National & $\begin{array}{l}\mathrm{FPG} \geq 126 \mathrm{mg} / \mathrm{dL} \text { and/or } \\
\text { history of diabetes }\end{array}$ & 5,645 & $\geq 30$ & DM: 11.1\% (M, 12.5\%; F, 9.8\%) & 23.2 \\
\hline [12] & 2001; National & $\begin{array}{l}\text { FPG } \geq 126 \mathrm{mg} / \mathrm{dL} \text { and/or } \\
\text { history of diabetes }\end{array}$ & 4,154 & $\geq 30$ & DM: $8.9 \%(M, 9.8 \% ; F, 8.2 \%)$ & 41.2 \\
\hline [12] & 2005; National & $\begin{array}{l}\mathrm{FPG} \geq 126 \mathrm{mg} / \mathrm{dL} \text { and/or } \\
\text { history of diabetes }\end{array}$ & 4,628 & $\geq 30$ & $\begin{array}{l}\text { DM: } 9.1 \%(\mathrm{M}, 10.2 \% ; \mathrm{F}, 7.9 \%) \\
\text { IFG: } 17.4 \%(\mathrm{M}, 21.3 \% ; \mathrm{F}, 13.7 \%)\end{array}$ & 68.0 \\
\hline $\begin{array}{l}\text { Unpublished } \\
\text { data }\end{array}$ & $\begin{array}{l}\text { 2007-2009; } \\
\text { National }\end{array}$ & $\begin{array}{l}\text { FPG } \geq 126 \mathrm{mg} / \mathrm{dL} \text { and/or } \\
\text { history of diabetes }\end{array}$ & 13,512 & $\geq 30$ & $\begin{array}{l}\text { DM: } 9.9 \%(\mathrm{M}, 11.0 \% ; \mathrm{F}, 8.9 \%) \\
\text { IFG: } 20.4 \%(\mathrm{M}, 24.1 \% ; \mathrm{F}, 16.8 \%)\end{array}$ & 72.3 \\
\hline
\end{tabular}

IFG, impaired fasting glucose; KNHANES, Korea National Health and Nutrition Examination Surveys; FPG, fasting plasma glucose; DM, diabetes mellitus.

Table 3. Prevalence of diabetes and IFG among Korean adults aged $\geq 30$ years in 2007-2009

\begin{tabular}{lrrrrrrrr}
\hline & \multicolumn{3}{c}{ Diabetes prevalence, $\%$} & & \multicolumn{3}{c}{ IFG prevalence, \% } \\
\cline { 2 - 4 } \cline { 7 - 8 } & Men & Women & Total & & Men & Women & Total \\
\hline $30-39$ & 3.5 & 1.7 & 2.6 & & 16.7 & 9.7 & 13.3 \\
$40-49$ & 8.2 & 4.7 & 6.5 & & 26 & 15.4 & 20.9 \\
$50-59$ & 16.1 & 9.7 & 13 & & 28.7 & 21.3 & 25.1 \\
$60-69$ & 23.8 & 23.4 & 20.9 & & 27.3 & 23.4 & 25.2 \\
$70+$ & 16.8 & 22.9 & 20.5 & & 27.4 & 21.2 & 23.6 \\
Total & 11.0 & 8.9 & 9.9 & & 24.1 & 16.8 & 20.4 \\
\hline
\end{tabular}

IFG, impaired fasting glucose.

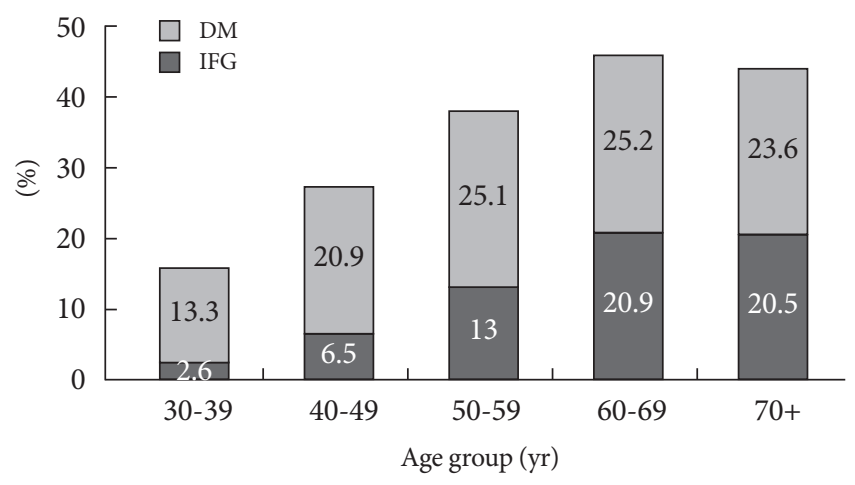

Fig. 1. Prevalence of diabetes and IFG among Korean adults in 2007-2009. DM, diabetes mellitus; IFG, impaired fasting glucose.

the prevalence of IFG was about 25\%. Diabetes and IFG were more frequent in men than in women.

Therefore, the prevalence of diabetes and IFG in Korea has rapidly increased in the past 40 years from $1.5 \%$ to $9.9 \%$ for diabetes and $20.4 \%$ for IFG (Fig. 2).

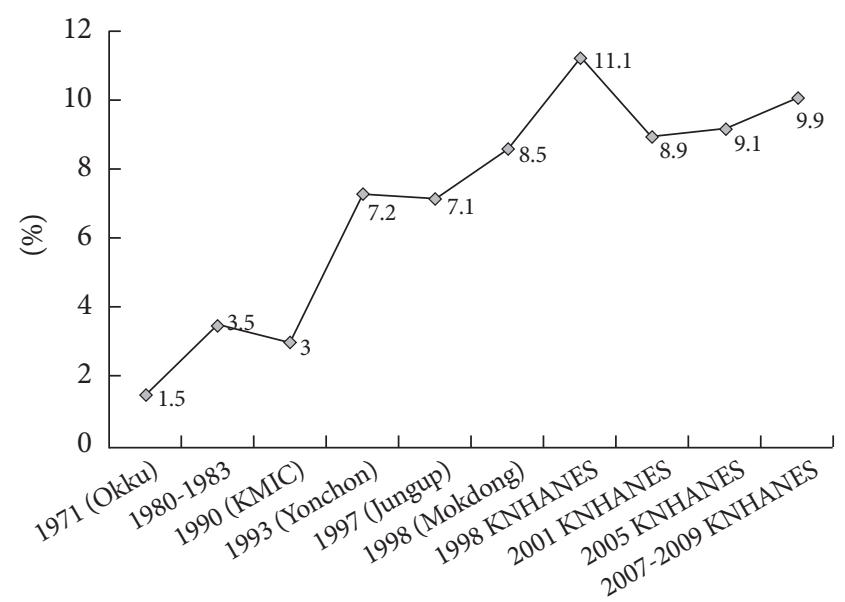

Fig. 2. Trend in prevalence of diabetes in Korea. KMIC, Korea Medical Insurance Corporation; KNHANES, Korea National Health and Nutrition Examination Surveys.

\section{INCIDENCE OF DIABETES AND RISK FACTORS}

In the 2-year follow-up study on diabetes in the rural area, the annual age-adjusted incidence of diabetes was 3.2\% in men and $1.5 \%$ in women [13]. Another rural cohort revealed that the age- and sex-adjusted incidence rate of diabetes was 16.3 per 1,000 person-years [14]. The incidence increased as age increased in both sexes. Age, male sex, and fasting and 2-hour glucose levels were significant independent risk factors for the development of diabetes. In the urban area, the age-adjusted annual incidence rate of diabetes for subjects $>40$ years of age at the baseline was $1.3 \%$ [9].

Based on the Task Force Team for Basic Statistical Study of Korean Diabetes Mellitus of the Korean Diabetes Association, 
Table 4. Estimates of diabetes prevalence in 2010 and 2030

\begin{tabular}{|c|c|c|c|c|c|c|}
\hline & \multicolumn{3}{|c|}{2010} & \multicolumn{3}{|c|}{2030} \\
\hline & \multicolumn{2}{|c|}{ Diabetes prevalence } & \multirow{2}{*}{$\begin{array}{l}\text { No. of people with } \\
\text { DM in the } 20-79 \\
\text { age group (000s) }\end{array}$} & \multicolumn{2}{|c|}{ Diabetes prevalence } & \multirow{2}{*}{$\begin{array}{c}\text { No. of people with } \\
\text { DM in the } 20-79 \\
\text { age group (000s) }\end{array}$} \\
\hline & $\begin{array}{c}\text { Regional/ } \\
\text { National, \% }\end{array}$ & Comparative, $\%$ & & $\begin{array}{c}\text { Regional/ } \\
\text { National, \% }\end{array}$ & Comparative, $\%$ & \\
\hline AFR & 3.2 & 3.8 & 12,089 & 3.7 & 4.7 & 23,947 \\
\hline MENA & 7.7 & 9.3 & 26,646 & 9.7 & 10.8 & 51,677 \\
\hline EUR & 8.6 & 6.9 & 55,388 & 10.1 & 8.1 & 66,455 \\
\hline UK & 4.9 & 3.6 & $2,139.6$ & 5.4 & 4.3 & $2,548.7$ \\
\hline Germany & 12.0 & 8.9 & $7,494.3$ & 13.5 & 10.2 & $8,013.7$ \\
\hline NAC & 11.7 & 10.2 & 37,362 & 13.6 & 12.1 & 53,207 \\
\hline USA & 12.3 & 10.3 & $26,813.6$ & 14.0 & 12.0 & $35,958.2$ \\
\hline SACA & 6.3 & 6.6 & 17,958 & 7.8 & 7.8 & 29,640 \\
\hline SEA & 7.0 & 7.6 & 58,662 & 8.4 & 9.1 & 100,962 \\
\hline India & 7.1 & 7.8 & $50,768.3$ & 8.6 & 9.3 & $87,036.1$ \\
\hline WP & 5.0 & 4.7 & 76,709 & 6.4 & 5.7 & 112,777 \\
\hline Korea & 9.0 & 7.9 & $3,292.4$ & 11.4 & 9.0 & $4,323.3$ \\
\hline Japan & 7.3 & 5.0 & $7,089.2$ & 8.0 & 5.9 & $6,878.9$ \\
\hline China & 4.5 & 4.2 & $43,157.2$ & 5.8 & 5.0 & $62,553.0$ \\
\hline Total & 6.6 & 6.4 & 284,814 & 7.8 & 7.7 & 438,667 \\
\hline
\end{tabular}

Regional/National: crude total population rates. Comparative: rates were adjusted to the age/sex composition of the world population to make regions more directly comparable. The data presented for adults are for types 1 and 2 diabetes combined. Data from Diabetes atlas. 4th ed. [21]. AFR, Africa; MENA, Middle East and North Africa; EUR, Europe; NAC, North America and Caribbean; SACA, South and Central America; SEA, Southeast Asia; WP, Western Pacific.

the annual incidence of diabetes among Korean adults aged 20 to 79 years was $0.76 \%$ ( $0.73 \%$ in men, $0.78 \%$ in women) in 2003 [15]. The incidence of diabetes increased with age, but with little difference between men and women. The incidence of diabetes in the 20 to 44,45 to 54,55 to 64 , and 65 to 79 age groups was $0.26 \%, 1.19 \%, 2.04 \%$, and $1.56 \%$ in men and $0.18 \%, 1.04 \%$, $2.09 \%$, and $2.25 \%$ in women, respectively.

A recent community cohort study showed that the annual incidence of type 2 diabetes was $1.33 \%$ to $2.35 \%$ in the $40 \mathrm{~s}$, $1.48 \%$ to $3.18 \%$ in the $50 \mathrm{~s}, 1.85 \%$ to $4.55 \%$ in the $60 \mathrm{~s}$, and $3.08 \%$ to $5 \%$ in the 70 s [11]. A relatively higher incidence was observed in the urban and male populations compared to the rural and female populations.

According to the follow-up study of women with previous gestational diabetes mellitus (GDM), Korean women with a history of GDM have a 3.5 times greater risk of developing postpartum diabetes than the general population [16]. Approximately $40 \%$ of women with previous GDM were expected to develop diabetes within 5 years postpartum.

IFG is the most important risk factor for diabetes. Based on the prospective cohort subjects with IFG, $16.6 \%$ of men and $6.5 \%$ of women had diabetes during the 4-year follow-up [17]. In addition, $21.2 \%$ of men and $15.2 \%$ of women developed type 2 diabetes in the obese group. Regular exercise is effective in preventing diabetes in people with IFG.

Smoking is an independent risk factor for diabetes [10,18]. Compared to never-smokers, current smokers had a 1.5 - to 1.7-fold increased risk.

Metabolic syndrome, as a clustering of metabolic abnormalities, is also an important risk factor for diabetes. According to the KNHANES cohort, subjects with metabolic syndrome had a 1.3-fold increased risk for diabetes [19].

Short sleep duration ( $\leq 5$ hour) is significantly associated with a 1.2-fold increase in general and abdominal obesity in Korean adults, and is thus associated with increased diabetes [20].

\section{GLOBAL TREND IN DIABETES AND IGT}

The International Diabetes Federation provides comprehen- 
sive estimates of the absolute numbers and prevalence of diabetes and IGT globally [21]. The total global prevalence of diabetes and IGT in 2010 was estimated at $6.6 \%$ and $7.9 \%$, respectively, and is expected to rise to $7.8 \%$ and $8.4 \%$, respectively, in 2030 (Table 4). It is estimated that 285 million and 344 million people worldwide will have diabetes and IGT, respectively, in 2010. By 2030, the number of people with diabetes and IGT is projected to increase to 438 million and 472 million, respectively, of the adult population. The largest increases will take place in the regions dominated by developing economies, such as Southeast Asia and the West Pacific region. The prevalence of diabetes and IGT among Korean adults aged 20 to 79 years in 2010 was estimated at $9.0 \%$ and $9.4 \%$, respectively, and is expected to rise to $11.4 \%$ and $11.5 \%$, respectively, in 2030 . The number of Korean people with diabetes and IGT was 3.3 million and 3.4 million, respectively, in 2010, and is expected to increase to 4.3 million and 4.4 million, respectively, in 2030.

\section{CONCLUSIONS}

Despite much evidence that diabetes can be prevented or delayed with lifestyle changes and weight loss or certain medications, the diabetic epidemic continues worldwide. The largest increases will take place in the developing regions, such as the West Pacific region, including Korea. With increasing obesity, especially in childhood, decreased physical activity, and improved longevity, diabetes and prediabetes is expected to dramatically increase more than previously projected.

Public efforts to introduce healthy lifestyle changes and systematic diabetes prevention programs are necessary to reduce the global epidemic of diabetes.

\section{CONFLICTS OF INTEREST}

No potential conflict of interest relevant to this article was reported.

\section{ACKNOWLEDGMENTS}

This study was supported by a grant from the Korea Health 21 R\&D Project, Ministry of Health and Welfare, Republic of Korea (A102065-1011-1070100).

\section{REFERENCES}

1. Wild S, Roglic G, Green A, Sicree R, King H. Global prevalence of diabetes: estimates for the year 2000 and projections for 2030. Diabetes Care 2004;27:1047-53.

2. Statistics Korea: 2009 statistical results about cause of death. Available from: http://www.index.go.kr (updated 2011 Aug 5).

3. Moon EJ, Jo YE, Park TC, Kim YK, Jung SH, Kim HJ, Kim DJ, Chung YS, Lee KW. Clinical characteristics and direct medical costs of type 2 diabetic patients. Korean Diabetes J 2008;32: 358-65.

4. Kim KS, Choi CH, Lee DY, Kim EJ. Epidemiological study on diabetes mellitus among rural Korean. J Korean Diabetes Assoc 1972;1:17-24.

5. Lee KW, Son HY, Kang SK, Bang BK, Park DH, Song HH, Min BS. Prevalence of diabetes mellitus and associated diseases among Korean subjects as studied with AMHTS. J Korean Diabetes Assoc 1984;8:5-15.

6. Jee SH, Appel LJ, Suh I, Whelton PK, Kim IS. Prevalence of cardiovascular risk factors in South Korean adults: results from the Korea Medical Insurance Corporation (KMIC) Study. Ann Epidemiol 1998;8:14-21.

7. Park Y, Lee H, Koh CS, Min H, Yoo K, Kim Y, Shin Y. Prevalence of diabetes and IGT in Yonchon County, South Korea. Diabetes Care 1995;18:545-8.

8. Kim YI, Choi CS, Kim SW, Lee JS, Kim HH, Lee MS, Lee SI, Park JY, Hong SK, Lee KU. Prevalence of diabetes mellitus and impaired glucose tolerance in Korean adults living in Jungup district, South Korea. J Korean Diabetes Assoc 1998;22:363-71.

9. Oh JY, Lee HJ, Hong ES, Hong YS, Sung YA, Lee SH. The prevalence and incidence of diabetes in Mokdong, Seoul. J Korean Diabetes Assoc 2003;27:73-83.

10. Cho NH, Chan JC, Jang HC, Lim S, Kim HL, Choi SH. Cigarette smoking is an independent risk factor for type 2 diabetes: a four-year community-based prospective study. Clin Endocrinol (Oxf) 2009;71:679-85.

11. Cho NH. The epidemiology of diabetes in Korea: from the economics to genetics. Korean Diabetes J 2010;34:10-5.

12. Choi YJ, Kim HC, Kim HM, Park SW, Kim J, Kim DJ. Prevalence and management of diabetes in Korean adults: Korea National Health and Nutrition Examination Surveys 19982005. Diabetes Care 2009;32:2016-20.

13. Shin CS, Lee HK, Koh CS, Kim YI, Shin YS, Yoo KY, Paik HY, Park YS, Yang BG. Risk factors for the development of NIDDM in Yonchon County, Korea. Diabetes Care 1997;20:1842-6. 
14. Song KH, Nam-Goomg IS, Han SM, Kim MS, Lee EJ, Lee YS, Lee MS, Yoon S, Lee KU, Park JY. Change in prevalence and 6-year incidence of diabetes and impaired fasting glucose in Korean subjects living in a rural area. Diabetes Res Clin Pract 2007;78:378-84

15. Task Force Team for Basic Statistical Study of Korean Diabetes Mellitus. Report of Task Force Team for Basic Statistical Study of Korean Diabetes Mellitus: diabetes in Korea 2007. 1st ed. Seoul: Goldfishery; 2007. p18-20.

16. Jang HC. Gestational diabetes in Korea: incidence and risk factors of diabetes in women with previous gestational diabetes. Diabetes Metab J 2011;35:1-7.

17. Um HD, Lee DC, Lee SY, Kim YS. A prospective cohort study of exercise and the incidence of type 2 diabetes in impaired fasting glucose group. J Prev Med Public Health 2008;41:45-50.

18. Jee SH, Foong AW, Hur NW, Samet JM. Smoking and risk for diabetes incidence and mortality in Korean men and women. Diabetes Care 2010;33:2567-72.

19. Khang YH, Cho SI, Kim HR. Risks for cardiovascular disease, stroke, ischaemic heart disease, and diabetes mellitus associated with the metabolic syndrome using the new harmonised definition: findings from nationally representative longitudinal data from an Asian population. Atherosclerosis 2010;213:57985

20. Park SE, Kim HM, Kim DH, Kim J, Cha BS, Kim DJ. The association between sleep duration and general and abdominal obesity in Koreans: data from the Korean National Health and Nutrition Examination Survey, 2001 and 2005. Obesity (Silver Spring) 2009;17:767-71

21. International Diabetes Federation: Diabetes atlas. 4th ed. Available from: http://www.idf.org (updated 2011 Aug 5). 